\section{Benefits of mission to Mars}

SIR-In his criticism of Bruce Murray's Commentary article advocating a manned mission to Mars, N. H. Horowitz (Nature 345,$760 ; 1990$ ) asserts that no justification exists for such a project that would be commensurate with its cost. Although he may well be correct that the immediate scientific objectives of such a mission could be performed more cheaply with robot spacecraft, there are nevertheless important social, political and scientific arguments that can be advanced in support of an ambitious manned space programme (of which a trip to Mars need form only a part). These include:

(1) The provision of work for the aerospace industry in a disarming world. As the industry employs over 1.3 million people in the United States alone, it will be politically necessary to find an alternative to weapons manufacture. I have argued elsewhere (New Scientist No. 1717, p. $67 ; 1990)$ that, by providing such an alternative, an expanded space programme may actually be able to assist the process of superpower disarmament.

(2) An expanded space programme would act as a peaceful driving force for the development of new technology and as a stimulus for scientific and technical education. Moreover, by increasing the public awareness of Earth's place in the Solar System, it may help to broaden minds when it comes to tackling important global economic and political problems. Horowitz is scornful of the entertainment aspect of manned spaceflight, but if people are entertained by something, they are likely also to learn from it, and a greater public understanding of our place in the cosmos would be no bad thing.

(3) The provision for a focus for international cooperation, the importance of which for global politics seems to be underestimated by Horowitz. From the point of view of enhancing international solidarity, it is particularly important that cooperation is achieved in areas that are highly visible to the public; space is an obvious candidate.

(4) From the scientific point of view, it can be argued that the long-term interests of astronomy and planetary science will require the construction of large structures in space. For example, the value of a lunar astronomical observatory has recently been reviewed by Burns et al. (Scientific American 262(3), 18; 1990). In any case, it is hard to see how human knowledge can fail to advance as a result of the expansion of people into the Solar System.

Thus, rather than opposing a manned space programme on grounds of cost, it seems to me that scientists should acknowledge its potential value, but argue that it should be financed by a transfer of resources from the military sector of the economy. It is fortunate that the ending of the Cold War has not only made this more realistic politically, but has also left the aerospace companies looking for new projects with which to fill their order books.

IAN CRAWFORD

Department of Physics and Astronomy, University College London,

Gower Street,

London WC1E 6BT, UK

\section{A funny old game}

SIR-Quantitative estimates may help to support your editorial plea for higher scores in Association Football (Nature 346, 92; 1990). But first, how well does the Poisson distribution represent the number of goals scored in matches between approximately evenly matched teams? The table shows the numbers of goals scored per team per full-time ( 90 -minute) game

\begin{tabular}{ccc}
\hline $\begin{array}{c}\text { Number } \\
\text { of goals }\end{array}$ & $\begin{array}{c}\text { Observed } \\
\text { frequency }\end{array}$ & $\begin{array}{c}\text { Expected } \\
\text { frequency }\end{array}$ \\
0 & 32 & 35.1 \\
1 & 47 & 38.1 \\
2 & 17 & 20.7 \\
3 & 2 & 7.5 \\
4 & 4 & 2.0 \\
5 & 2 & 0.4 \\
$>5$ & 0 & 0.1 \\
Total & 104 & 103.9 \\
\hline
\end{tabular}

in the 52 matches of the recent World Cup series, together with the numbers expected assuming a Poisson distribution with a mean of 1.09 , as actually realized.

A perfect fit is not of course to be expected, as all teams are not approximately evenly matched. Nevertheless, the agreement seems reasonable and if, as is conventional, small numbers are eliminated by pooling the last four rows, the differences are not statistically significant $\left(\varkappa^{2}=3.4,3\right.$ d.f., $\left.P>0.2\right)$.

Accepting the Poisson model as reasonable, then, the implications of a mean scoring rate of about 1 goal per team per 90 -minute game are (1) that the probability of a draw is about 1 in 3 almost irrespective of the relative strengths of the two teams and (2) that if team A is twice as strong as team B in the sense that they have 'expected' scoring rates against each other of 1.33 and 0.67 respectively, then the probability that team A wins a particular match is only slightly greater than 1 in 2 . On the other hand, with a mean scoring rate of 4 goals per team, the probability of a draw would fall to about 1 in 9 , and the probability that team A (with mean 5.33) beats team B (with mean 2.67) would increase to nearly 80 per cent.

There is little doubt that such an increase in scoring rate would make the game both fairer (in the sense of producing the right result) and more rewarding to watch and play. The ruling bodies of the sport would do well to ponder these mathematical facts of life, but the implications for the football pools are another matter altogether.

ANDREW D. CAROTHERS

23 Dick Place,

Edinburgh EH9 2JU, UK

\section{Help for Romania}

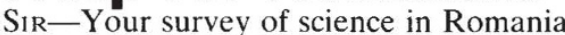
(Nature 344, 613-615; 1990) was generally accurate, but some references to Elena Ceausescu need correction. In fact, she was never called "Professor". This was the only title she could not get in this country and that may be why she hated us, the professors, so much. As a result, she used her unlimited powers to stop all promotions to this academic title in the past 12 years or so. The title she boasted and which was used by the media was "academician doctor engineer", which sounds ridiculous. The addition of her name on research papers in polymer chemistry reporting work done by others is perhaps one of the greatest frauds in science, and all electronic databases should be corrected accordingly. Unfortunately, the printed version of Chemical Abstracts and so on cannot be corrected.

In spite of the difficulties of academic life in Romania during the years of dictatorship, there were many scientists who continued to carry out fundamental research (with almost no money), to cooperate with foreign colleagues (often illegally), to attend international meetings and to publish papers in international journals and even books. (I myself managed with great difficulty during this period to have four books published in the West.) Perhaps this could be called "scientific dissidence".

I have three suggestions for ways in which our colleagues in the West could help scientists in Romania and elsewhere in Eastern Europe:

(1) Send reprints of publications to people working in the same field in Eastern Europe without waiting for a request.

(2) If you have sophisticated equipment, provide opportunities for joint research and collaboration

(3) If somebody in Eastern Europe manages to get a travel grant or a research fellowship, offer him the opportunity to work in your laboratory or research group.

None of these gestures would entail a heavy financial burden, but they would make all the difference to researchers in Eastern Europe.

Babes-Bolyai University,

IONEL HAIDUC

R-3400 Cluj-Napoca

Romania 